\title{
Efficacy of Ondansetron in the Prevention or Treatment of Post-operative Delirium- a Systematic Review
}

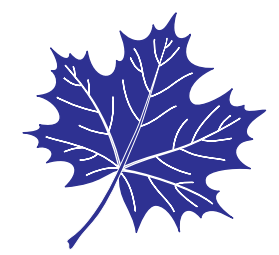

Nihal Haque, MD, FRCPC ${ }^{1}$, Raza M. Naqvi, MD, FRCPC ${ }^{2}$, and Monidipa Dasgupta, MD, FRCPC 3 ,4

${ }^{1}$ Division of Geriatric Medicine, Department of Medicine, North York General Hospital, Toronto, ON; ${ }^{2}$ Markham Stouffville Hospital, Markham, ON; ${ }^{3}$ Lawson Health Institute, London, ON, Canada; ${ }^{4}$ Divison of Geriatric Medicine, Department of Medicine, Western University, London, ON, Canada

https://doi.org/10.5770/cgj.22.266

\begin{abstract}
Background

Post-operative delirium (POD) is associated with higher rates of functional decline and death. Ondansetron is a serotonin antagonist which could represent a therapeutic or preventive option in POD.
\end{abstract}

\section{Methods}

A systematic review of MEDLINE, EMBASE, CENTRAL, and PsychINFO was performed. Three randomized controlled trials (RCTs) met inclusion criteria (intervention of ondansetron compared to a control group).

\section{Results}

Two RCTs examined ondansetron for the treatment of POD in patients after cardiac or post-trauma surgery in the ICU. Studies assessed either a one-time dose or doses for 3 days of ondansetron or haloperidol IV. They suggested similar reductions in average delirium scores and rates in both interventions, although one study suggested ondansetron to be associated with higher rates of rescue haloperidol use. One RCT examined prophylactic ondansetron versus placebo IV, for five days postoperatively, to prevent POD in orthopedic patients. There were significantly fewer delirious patients in the ondansetron group. In general, studies had major methodological limitations and were very heterogenous in study tools, interventions used, and populations studied.

\section{Conclusions}

Ondansetron may be an effective agent for the prevention or treatment of POD, but studies are few and of poor quality, thus making the conclusions tenuous. Further large RCTs are needed.

Key words: delirium, cognitive disorders, geriatric medicine, neurotransmitters

\section{INTRODUCTION}

Delirium is defined as the acute onset of fluctuating cognition and inattention associated either with altered level of consciousness or disorganized thought processes. ${ }^{(1)}$ Postoperative delirium (POD) affects up to 50 per cent of elderly inpatients. ${ }^{(2)}$ It is associated with an increased length of stay, risk of functional and cognitive decline, institutionalization, and death. ${ }^{(3)}$ This association is independent of other important confounding factors such as prior functional status, nursing home residence, dementia, and co-morbidities. ${ }^{(4)}$

Over 300 million surgeries are performed worldwide every year. ${ }^{(5)}$ One-third of all inpatient surgeries are performed on adults 65 years or older, and delirium costs up to $\$ 150$ billion every year in the United States. ${ }^{(6)}$ This translates into approximately 50 million patients a year worldwide, where preventing or treating POD would save health care costs and lead to improvements in post-operative morbidity and mortality.

Serotonin has been postulated to play in role in delirium, and observational studies have shown higher levels in delirious patients. ${ }^{(7)}$ This is further supported by the fact that delirium is a major manifestation of serotonin syndrome. Ondansetron is a serotonin antagonist specific for the 5-HT3 receptor which is routinely used post-operatively for nausea and vomiting. It has a better safety profile than haloperidol, which is the most commonly used agent for treating and preventing POD. ${ }^{(8)}$ There has been interest in the literature about the role of ondansetron in the prevention and treatment of POD. Earlier observational studies found a positive role for ondansetron in the treatment of POD after cardiac surgery. ${ }^{(9)}$ 
We performed a systematic review of the literature in order to summarize randomized controlled trials (RCTs) examining the role of ondansetron in the prevention and treatment of POD.

\section{METHODS}

A systematic search of the EMBASE, MEDLINE, Cochrane, and PsychINFO databases was performed from 1949-May 2016. The search strategy included the keywords "delirium", "delirious", "ondansetron", "serotonin agents", and generic/brand names for other members of the -setron family. Inclusion criteria included RCTs which examined the use of ondansetron versus placebo (or other agents) in the prevention or treatment of POD in patients aged 17 years or older. All types of surgeries were included. Exclusion criteria included observational studies with no control group, serotonergic agents other than 5-HT3 receptor antagonists, and non-English articles. Article screening and data abstraction were performed by two independent authors. Any conflicts were resolved by a third author. The following data were extracted: type of comparator group, numbers of patients in each intervention/comparator group, types of surgeries performed, setting of patient, average age, delirium symptom measures, and the percentage of delirious patients in each group at the end of the study period. If other outcomes relevant to delirium were reported, such as functional status or cognitive scores, these were also extracted. A schematic flowchart of the study methodology is provided in Figure 1.

\section{RESULTS}

A total of 642 unique articles were identified using the initial search strategy. After applying the inclusion and exclusion

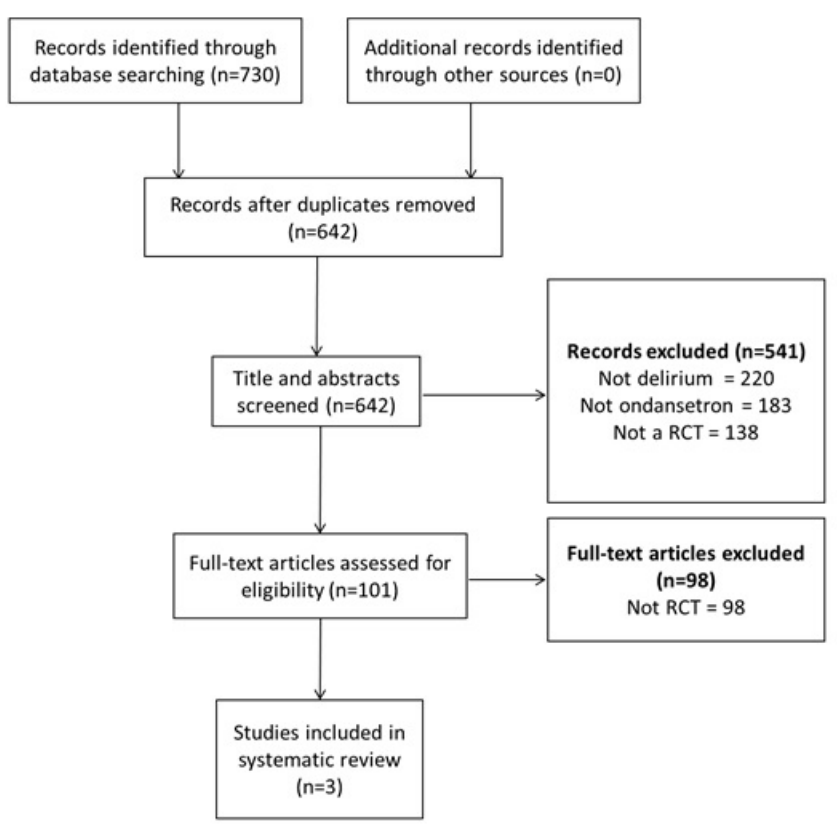

FIGURE 1. Methodology of systematic review criteria, two RCTs examining the role of ondansetron in the treatment of delirium were identified. One RCT examining the role of ondansetron in the prevention of delirium was also identified. The data could not be pooled due to significant heterogeneity in the patient populations, intervention doses, durations of study, and scales used to define and measure the severity of delirium. A modified Jadad scale was used to assess the quality of the studies (Table 1). ${ }^{(10)}$ Overall, they were of lower quality, with major limitations being not reporting the methods of randomization or blinding and not describing the percentage of patients completing the intervention in each arm (Table 1). The demographics and results of each study are summarized in Table 2.

\section{Treatment of Post-operative Delirium}

Tagarakis et al. ${ }^{(11)}$ examined 80 delirious patients with a mean age of 71 years post-cardiac surgery. Patients with a history of psychiatric disease were excluded. Patients were diagnosed with delirium based on a 4-point scale: $0=$ normal, $1=$ restless and mild confusion, $2=$ disoriented but cooperative, $3=$ disoriented and uncooperative, $4=$ violent and aggressive with hallucinations. The patient's delirium scores were measured before and 10 minutes after the administration of the drug. Patients received either ondansetron $8 \mathrm{mg}$ or haloperidol $5 \mathrm{mg}$ intravenously (IV) as a single dose on diagnosis of delirium. It was unclear how the diagnosis of delirium was actually made. There were no significant differences between the groups in terms of important variables such as type of cardiac surgery performed.

The percentage of delirious patients in the ondansetron and haloperidol groups 10 minutes post administration were 17.5 per cent and 15 per cent, respectively (n.s.) (Table 2). Average delirium scores decreased similarly in both groups: from 3.1 to 1.2 in the ondansetron group and 3.1 to 1.3 for the haloperidol group (n.s.) (Table 2). There were no long-term data on delirium rates or scores provided.

Bakri et al. ${ }^{(12)}$ examined 96 trauma patients in the ICU with a mean age of 31 years. Multiple surgeries were included and major categories were 25 per cent general surgery, 27 per cent neurosurgery and 26 per cent maxillofacial surgery. Patients with neurologic diseases, hearing loss, intracranial injury, strokes, coma or language barrier were excluded. Delirium scores were calculated using the Intensive Care Delirium Screening Checklist (ICDSC). The ICDSC is an 8-point scale which gives one point for each of the following: altered level of consciousness, inattention, disorientation, hallucinations/delusions/psychosis, psychomotor agitation or retardation, inappropriate speech/mood, sleep-wake cycle disturbances, and fluctuating symptoms. Patients were defined as having delirium if they scored four or more points on the ICDSC scale. Delirious patients were randomly assigned to three groups and given either $1 \mu \mathrm{g} / \mathrm{kg}$ dexmedetomidine or $4 \mathrm{mg}$ ondansetron or $5 \mathrm{mg}$ haloperidol IV twice daily for three consecutive days. The ICDSC score was recalculated 
TABLE 1.

Modified Jadad scores for assessing the quality of the RCTs examined in this review (Yes: 1 point, No: -1 point, Not described: 0 points)

\begin{tabular}{lccc}
\hline & Tagarakis et al. $^{(11)}$ & Bakri et al. $^{(12)}$ & Papadopoulos et al. $^{(13)}$ \\
\hline Was the study described as randomized? & Yes & Yes & \multicolumn{1}{c}{ Yes } \\
Was the method of randomization appropriate? & Not described & Yes & Nescribed \\
Was the study described as blinded? & Yes & Yes & Yes \\
Was the method of blinding appropriate? & Not described & No described & No \\
Was there a description of withdrawals and dropouts? & No & Yes & Yes \\
Was there a clear description of inclusion/exclusion criteria? & No & No & No \\
Was the method used to assess adverse effects described? & Yes & Yes & $4 / 8$ \\
Were the methods of statistical analysis described? & $2 / 8$ & & $2 / 8$ \\
Total Score & &
\end{tabular}

1 hour after administration of medications and an average was calculated for each day. There was no significant difference between the groups in terms of important variables such as type of surgery, duration of surgery, mean injury severity score, and rates of mechanical ventilation on admission.

ICDSC scores were similarly decreased across all three groups with no statistically significant difference (Table 2 ). Even though the percentage of delirious patients also decreased similarly across the three groups, the mean total dose of rescue haloperidol was significantly higher in the ondansetron group (Table 2). Furthermore, the use of deliriumcausing agents, such as catheter use, nasogastric tubes, and physical restraints, were not measured across the groups. They also stated that there was no significant prolongation of the QTc interval during the study period, but data on QT interval were not provided.

\section{Prevention of Post-operative Delirium}

Papadopoulos et al. ${ }^{(13)}$ examined the role of prophylactic ondansetron in the prevention of POD. They examined 106 patients with a mean age of 71 years post-orthopedic (hip or femoral fracture) surgery. Any patients greater than 40 years were included. Patients were excluded if they had a current or past history of Parkinson's or Alzheimer's disease or other psychiatric illness, serious hearing or vision impairment, current use of tranquilizers or anti-depressants, history of drug or alcohol abuse, or had a contraindication to ondansetron. They divided them into two groups: ondansetron $8 \mathrm{mg}$ IV or only placebo IV once daily for five days post-operatively. Patients were diagnosed with delirium if their Confusion Assessment Method (CAM) test was positive. CAM involves the following criteria: 1) acute onset and fluctuating course, 2) inattention and either 3) disorganized thinking, or 4) altered level of consciousness. ${ }^{(1)}$ Each patient was evaluated preoperatively to rule out delirium and postoperatively on days two, three, four, and five, post-operatively. There were no significant differences between the groups in terms of important variables such as age, duration of anesthesia, stroke history or prior history of alcohol consumption. Study authors did not mention how delirium was managed, nor whether haloperidol or other antipsychotics were used in any of the two groups.

The percentage of delirious patients decreased significantly in the ondansetron group starting on post-operative Day three and persisted to Day five $(p<.001)$ (Table 2$)$. In terms of long-term outcomes, the average Mini-Mental Status Examination (MMSE) score was five points better in the ondansetron group at 30 days $(p<.001)$ (Table 2). This occurred despite the fact that the baseline MMSE was two points lower in the ondansetron group. Finally, the Instrumental Activities of Daily Living (IADL) scores were also significantly better at 30 days in the ondansetron group $(p<.001)$ (Table 2). Even though the number of delirious patients was significantly lower in the ondansetron group, this did not translate into a statistically significant shorter length of stay (7.74 days in the ondansetron group versus 8.127 days in the placebo group) $(p>.05)$.

\section{DISCUSSION}

We found two RCTs looking at the role of ondansetron in the treatment of delirium. Bakri et al. ${ }^{(12)}$ found no statistically significant difference between ondansetron and haloperidol in delirium symptom scores and number of patients whose delirium resolved. There are various caveats to this conclusion. First, the ondansetron group needed statistically significantly higher doses of rescue haloperidol in this study. Tagarakis et $a l .{ }^{(11)}$ also did not show any significant difference between the haloperidol and ondansetron groups, but there was no mention of whether rescue haloperidol was received by the ondansetron group. Second, the average age of patients is 40 years younger in the Bakri study. Since delirium in non-elderly patients is usually caused by more severe illness, ${ }^{(14)}$ it might very well be that ondansetron works better for delirium associated with milder illness, but not for delirium associated with severe illness. It is also difficult to directly compare the 
severity of delirium across the studies since they used different rating scales. Furthermore, given the younger average age of patients in the Bakri study, it is hard to generalize the results to the geriatric population. Third, Bakri et al. ${ }^{(12)}$ examined patients in the ICU, whereas Tagarakis et al. ${ }^{(11)}$ examined patients on the floor. These are two different populations, thus making comparisons across studies difficult. Fourth, the
Tagarakis study only assessed the effects of a single dose of IV ondansetron or haloperidol, as opposed to use over several days. This may lead to an under-estimate of its effects over days. Fifth, both these studies assessed the use of ondansetron in comparison to IV haloperidol which is not necessarily the first line treatment for POD in the geriatric population. Finally, only the Bakri study mentioned that there was no

TABLE 2.

Characteristics and results of each study examined in this review

\begin{tabular}{|c|c|c|c|}
\hline & \multicolumn{2}{|c|}{ Treatment of $P O D$} & \multirow{2}{*}{$\frac{\text { Prevention of POD }}{\text { Papadopoulos et al. } .^{(13)}}$} \\
\hline & Tagarakis et al. ${ }^{(11)}$ & Bakri et al. ${ }^{(12)}$ & \\
\hline Total number of patients & 80 & 96 & 106 \\
\hline Average age (years) & 71 & 31 & 71 \\
\hline Gender (Percentage male) & 66 & 91 & 44 \\
\hline $\begin{array}{l}\text { Definition or grading } \\
\text { severity of delirium }\end{array}$ & $\begin{array}{l}\text { 4-point scale } \\
\text { to assess severity } \\
\text { Unclear as to how } \\
\text { delirium was defined }\end{array}$ & $\begin{array}{l}\text { Intensive Care Delirium Screening } \\
\text { Checklist (ICDSC) - 8-point scale } \\
\text { to assess severity } \\
4 \text { points defined presence of delirium }\end{array}$ & $\begin{array}{c}\text { Confusion Assessment Method (CAM) } \\
\text { positive to assess presence or } \\
\text { absence of delirium } \\
\text { (severity not measured) }\end{array}$ \\
\hline Duration of intervention & $\begin{array}{l}\text { Once on diagnosis } \\
\text { of delirium }\end{array}$ & 3 days & 5 days \\
\hline Type of intervention & $\begin{array}{l}\text { Ondansetron } 8 \mathrm{mg} \mathrm{IV} \mathrm{or} \\
\text { Haloperidol } 5 \mathrm{mg} \mathrm{IV} \\
\text { once }\end{array}$ & $\begin{array}{l}\text { Dexmedetomidine } 1 \mu \mathrm{g} / \mathrm{kg} \text { or } \\
\text { Ondansetron } 4 \mathrm{mg} \mathrm{IV} \mathrm{or} \\
\text { Haloperidol } 5 \mathrm{mg} \mathrm{IV} \\
\text { twice daily for } 3 \text { days }\end{array}$ & $\begin{array}{c}\text { Ondansetron } 8 \mathrm{mg} \text { IV or placebo IV } \\
\text { once daily for } 5 \text { days }\end{array}$ \\
\hline Setting & Floor & Trauma Intensive Care Unit & Floor \\
\hline Surgeries & Cardiac surgery & $\begin{array}{c}\text { General Surgery }(25 \%) \\
\text { Neurosurgery }(27 \%) \\
\text { Maxillofacial surgery }(26 \%)\end{array}$ & Orthopedic surgery \\
\hline $\begin{array}{l}\text { Mean duration of surgery } \\
\text { under anesthesia (min) }\end{array}$ & NR & 211 & 188 \\
\hline Delirium Scores & $\begin{array}{l}\text { Ondansetron: } 3.1 \rightarrow 1.2 \\
\text { Haloperidol: } 3.1 \rightarrow 1.3\end{array}$ & $\begin{array}{c}\text { Dexmedetomidine: } 6.7 \rightarrow 2.9^{\mathrm{a}} \\
\text { Ondansetron: } 6.4 \rightarrow 3.5 \\
\text { Haloperidol: } 6.5 \rightarrow 3.4\end{array}$ & NR \\
\hline $\begin{array}{l}\text { Percentage of patients } \\
\text { delirious at end of study } \\
\text { period }\end{array}$ & $\begin{array}{l}\text { Ondansetron: } 17.5 \\
\text { Haloperidol: } 15\end{array}$ & $\begin{array}{l}\text { Dexmedetomidine: } 9.4 \\
\text { Ondansetron: } 18.75 \\
\text { Haloperidol: } 6.25\end{array}$ & $\begin{array}{c}\text { Ondansetron: } 0^{\mathrm{a}} \\
\text { Placebo: } 27 \\
\text { (differences significant } \\
\text { by post-operative Day 3) }\end{array}$ \\
\hline $\begin{array}{l}\text { Average total dose of } \\
\text { rescue haloperidol in each } \\
\text { group (mg) }\end{array}$ & NR & $\begin{array}{l}\text { Dexmedetomidine: } 1.1 \\
\text { Ondansetron: } 2.1^{\mathrm{a}} \\
\text { Haloperidol: } 0.9\end{array}$ & NR \\
\hline Toxicity data & NR & $\begin{array}{l}\text { Stated no significant prolongation of } \\
\text { QT intervals but data not provided }\end{array}$ & NR \\
\hline Other relevant outcomes & N/A & N/A & 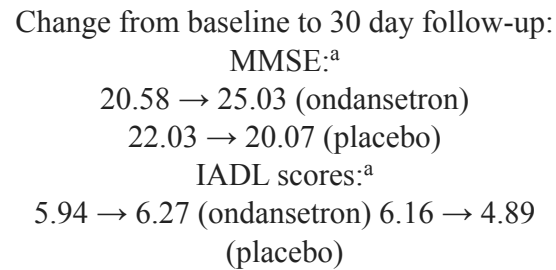 \\
\hline
\end{tabular}

${ }^{a}$ Numbers are statistically significant results.

$\mathrm{NR}=$ not reported 
significant QTc prolongation, but neither study provided data on the safety of ondansetron in these populations. Given these caveats, the evidence for the treatment of POD using ondansetron is weak.

We found one RCT which assessed the efficacy of ondansetron in the prevention of delirium (Papadopoulos et $a .^{(12)}$ ). The study showed a statistically and clinically significant decrease in the number of delirious patients in the ondansetron group starting on the third post-operative day. It also showed significantly better IADL and MMSE scores at the 30 day follow-up. The study excluded patients who are most prone to POD: patients with a diagnosed history of dementia or serious visual or auditory impairment. However, the average MMSE range was 20 to 23 , indicating a mild degree of cognitive impairment did exist in the patients enrolled. While this study shows several statistically significant results, it is important to note that a priori power calculations were not performed for multiple comparisons. Furthermore, the percentage of patients needing rescue medications was not reported. As seen in the study by Bakri et al., ${ }^{(12)}$ this can overestimate the therapeutic effect of ondansetron. Finally, no safety data regarding QT interval prolongation in these patients were provided. Since patients in this age group are on various QT prolonging medications, it would be important to know the extent of QT prolongation with the administration of ondansetron for five days.

Notwithstanding these limitations, if the improvements in IADL scores and MMSE scores at 30 days are sustained, this would represent an important role for ondansetron in the prevention of the consequences attributable to POD, and may lead to other benefits. Although very preliminary, if these results can be replicated, this could lead to increased indirect cost savings through the use of ondansetron. Delirium leads to higher rates of post-discharge institutionalization due to deficits in cognition and subsequent IADL abilities. Ondansetron could potentially decrease the rates of post-discharge institutionalization by preserving MMSE and IADL loss in cases of POD as demonstrated by the Papadopoulos study. Given the study design, the data for the prevention of POD using ondansetron are stronger than that for treatment.

The leading pathophysiologic explanation for delirium is the neurotransmitter hypothesis which states that decreased oxidative metabolism in the brain causes aberrations in various neurotransmitter systems. ${ }^{(14)}$ In particular, POD in the elderly can be a combination of cholinergic deficit, dopaminergic excess, and either serotonergic excess or deficit. ${ }^{(15)}$ Thus far, most studies on prevention or treatment of POD have focused on the dopaminergic system. Studies suggest that antipsychotics (which block the effects of dopamine excess) decreases the overall risk of developing POD. ${ }^{(16)}$ However, anti-psychotics have deleterious extrapyramidal side effects, as well as other side effects which can limit their use. Ondansetron does not have these side effects and, as such, could be an attractive alternative to anti-psychotic drugs in the prevention or treatment of delirium and may act as an anti-psychotic sparing agent. More head-to-head comparison studies would be required before this could be recommended. 5-HT3 receptors have been isolated in cholinergic axon terminals, and ondansetron can increase cholinergic output by acting on these receptors. ${ }^{(17)}$ This interplay between the cholinergic and serotonergic system provides a mechanistic basis for our findings. Furthermore, these studies support the hypothesis of serotonergic excess rather than deficit in the pathophysiology of delirium.

The strengths of our review include the fact that we used a systematic methodology to review the existing literature. We also employed independent reviewers to abstract and analyze the data. Limitations of our review are that we did not extend our search to non-English sources and abstracts from scientific meetings, which may have limited our search. Other limitations include the paucity of studies in this area, methodologic features of included studies, and the small sample sizes of the included studies.

\section{CONCLUSION}

We found only three RCTs that assessed the use of ondansetron in the prevention or treatment of POD, highlighting the lack of good studies supporting its use. Ondansetron is a potentially effective agent for the prevention of POD. The evidence for the treatment of established POD is less robust, given the major limitations in those studies. The quality of the underlying evidence was low and there was significant heterogeneity between the studies. As such, a pooled analysis could not be completed. However, we found some evidence of a possible benefit in ondansetron, but this needs further study. If more data indicated that ondansetron is indeed effective in preventing POD, it would be an appropriate first step in the minimization of antipsychotic use and its attendant risks in the hospital. Even though IV ondansetron is significantly more expensive than IV haloperidol ( $\$ 4$ vs. $\$ 1.25$ per dose), we believe it would still be cost-effective, given the amount of health-care dollars associated with POD and its complications. A large randomized controlled trial is required in order to provide more evidence for the routine use of ondansetron in the prevention or treatment of POD.

\section{ACKNOWLEDGEMENTS}

We would like to acknowledge the efforts of our clinical librarian Alla Iansavitchene in helping us design and execute the search strategy. We would also like to thank the Program of Experimental Medicine (POEM) at the University of Western Ontario for funding support.

\section{CONFLICT OF INTEREST DISCLOSURES}

The authors declare that no conflicts of interest exist. 


\section{REFERENCES}

1. Inouye SK, Van Dyck CH, Alessi CA, et al. Clarifying confusion: The confusion assessment method: a new method for detection of delirium. Ann Intern Med. 1990;113(12):941-48.

2. Inouye SK. Delirium in older persons. $N$ Engl J Med. 2006;354(11):1157-65. Available from: https://www.nejm.org/ doi/full/10.1056/NEJMra052321

3. Rudolph JL, Marcantonio ER. Postoperative delirium: acute change with long-term implications. Anesth Analg. 2011;112(5):1202-11.

4. Witlox J, Eurelings LSM, de Jonghe JFM, et al. Delirium in elderly patients and the risk of postdischarge mortality, institutionalization, and dementia: a meta-analysis. JAMA 2010;304(4):443-51. Available from: http://www.ncbi.nlm. nih.gov/pubmed/20664045

5. Weiser TG, Haynes AB, Molina G, et al. Estimate of the global volume of surgery in 2012: an assessment supporting improved health outcomes. Lancet. 2015;385(S11). Available from: https://www.thelancet.com/journals/lancet/article/PIIS01406736(15)60806-6/fulltext

6. American Geriatrics Society Expert Panel on Postoperative Delirium in Older Adults. Postoperative delirium in older adults: Best Practice Statement from the American Geriatrics Society. $J$ Am Coll Surg. 2015;220(2):136-48.

7. van der Mast RC, Fekkes D. Serotonin and amino acids: partners in delirium pathophysiology? Semin Clin Neuropsychiatry. 2000;5(2):125-31. Available from: http://www.ncbi.nlm.nih. gov/pubmed/10837101

8. Tricco AC, Soobiah C, Antony J, et al. Safety of serotonin (5HT3) receptor antagonists in patients undergoing surgery and chemotherapy: protocol for a systematic review and network meta-analysis. Syst Rev. 2013;2(1):46. Available from: http:// www.ncbi.nlm.nih.gov/pubmed/23810058

9. Bayindir O, Akpinar B, Can E, et al. The use of the 5-HT3receptor antagonist ondansetron for the treatment of postcardiotomy delirium. J Cardiothorac Vasc Anesth . 2000;14(3):288-92.
10. Oremus $\mathrm{M}$, Wolfson $\mathrm{C}$, Perrault $\mathrm{A}$, et al. Interrater reliability of the modified Jadad quality scale for systematic reviews of Alzheimer's disease drug trials. Dement Geriatr Cogn Disord. 2001;12(3):232-36

11. Tagarakis GI, Voucharas C, Tsolaki F, et al. Ondansetron versus haloperidol for the treatment of postcardiotomy delirium: a prospective, randomized, double-blinded study. J Cardiothorac Surg. 2012;7:25.

12. Bakri MH, Eman AI, Ibrahim A. Comparision of dexmedetomidine or ondansetron with haloperidol for treatment of postoperative delirium in trauma patients admitted to intensive care unit: randomized control trial. Anaesth, Pain Intens Care. 2015;19(2):118-23.

13. Papadopoulos G, Pouangare M, Papathanakos G, et al. The effect of ondansetron on postoperative delirium and cognitive function in aged orthopedic patients. Minerva Anestesiol. 2013;80(4):444-51

14. van der Mast RC. Pathophysiology of delirium. $J$ Geriatr Psychiatry Neurol. 1998;11(157-8):138-45.

15. van der Mast RC. Postoperative delirium. Dement Geriatr Cogn Disord. 1999;10(5):401-05. Available from: http://www.ncbi. nlm.nih.gov/pubmed/10473947

16. Teslyar P, Stock VM, Wilk CM, et al. Prophylaxis with antipsychotic medication reduces the risk of post-operative delirium in elderly patients: a meta-analysis. Psychosomatics. 2013;54(2):124-31.

17. Maura G, Andrioli GC, Cavazzani P, et al. 5-Hydroxytryptamine3 receptors sited on cholinergic axon terminals of human cerebral cortex mediate inhibition of acetylcholine release. $J$ Neurochem. 1992;58(6):2334-37.

Correspondence to: Nihal Haque, MD, FRCPC, Senior's Health Centre, North York General Hospital, 2 Buchan Court, North York, ON, M2J 5A3

E-mail: nihal.haque@nygh.on.ca 